\title{
O pensamento criativo na metodologia no Design
}

\author{
Creative Thinking in Design Methodology
}

PONTE, Raquel; Doutor em Design pela ESDI; Professora de Comunicação Visual Design da UFRJ raquelponte@gmail.com

NIEMEYER, Lucy; Pós-doutor em Design pelo IADE; Professora do UNIDCOM/IADE - Universidade Europeia - Lisboa / UERJ / UFRJ

lucyniemeyer@gmail.com

\section{Resumo}

Lawson e Dorst afirmaram, em seu livro Design expertise (2009), ser o design uma mistura de racionalidade e criatividade - uma esquizofrenia, em suas palavras, que caracterizaria este campo. Essa afirmação, ainda que em tom de brincadeira, torna evidente haver nesta área uma visão dicotômica entre as capacidades analíticas e sintéticas. Este artigo visa mostrar, apresentando o conceito de projeto, como a criatividade é parte integrante das metodologias usadas no design, ainda que a racionalidade é que tenha se afirmado, ao longo da histórica, como legitimadora da eficiência no design. É a capacidade criativa sintética que faz com que o design seja uma ciência da invenção e não da descoberta (Buchanan, 1995a). Portanto, este artigo buscar mostrar como a metodologia possui um aspecto criador, assim como o resultado do processo de criação necessita do pensamento sintético que seleciona a alternativa mais adequada ao problema enfrentado.

Palavras Chave: criatividade; metodologia; projeto e ciência da invenção.

\begin{abstract}
Lawson and Dorst stated in their book Design expertise (2009) that design is a mixture of rationality and creativity - a schizophrenia, in their words, that would characterize this field. This statement, albeit in jest, makes it clear that there is a dichotomous view in this area between analytical and synthetic capabilities. This paper aims to show, presenting the concept of design, how creativity is an integral part of the methodologies used in design, although the rationality is that it has been affirmed, throughout the history, as legitimating of the efficiency in the design. It is the synthetic creative capacity that makes design a science of invention and not a science of discovery (Buchanan, 1995a). Therefore, this paper seeks to show how the methodology has a creative aspect, just as the result of the creation process requires the synthetic thought that selects the most appropriate alternative to the faced problem.
\end{abstract}

Keywords: creativity; metodology; project and science of invention. 


\section{0 projeto no design}

Segundo Buchanan (1995a), até o Renascimento, a atividade de gerar artefatos se constituía em dois momentos indissociáveis: o planejamento e a previsão (forethought) e o fazer (making), ambos nas mãos dos artesãos. Porém essa configuração alterou-se com a mudança dos meios produtivos, a qual acarretou o afastamento das fases de ideação e execução, de modo que profissionais diferentes passaram a ficar responsáveis por uma e outra. O projeto ficou a cargo do designer, enquanto a produção, sob a responsabilidade do operário da fábrica.

O projeto, segundo o historiador de arte Giulio Carlo Argan no texto "A História na metodologia do projeto", "[...] é a relação direta entre uma atividade puramente intelectual e uma atividade manual" (1993, p.1). Sua concepção tem origem datada historicamente, pois há um momento bem definido em que se inicia a separação entre o momento mental e a execução: o alvorecer da cultura humanista no século XV, que teve seu ápice no lluminismo (século XVIII). Argan afirma que, até então, predominava nas artes a cultura do modelo. Na Antiguidade, principalmente, havia uma noção de arte - entendida pelos gregos em seu tempo como arte manual, ofício de artífices, e não como hoje a pensamos, em seu sentido estético (SILVA; SILVA, 2013, p.3-4) - como imitação, mímese. A partir do Renascimento, inicia-se uma civilização do projeto, que considera o momento projetual de fundamental importância para a atividade humana, sendo esta uma das marcas do início da cultura moderna.

Como afirma o antropólogo Bruno Latour (1994), o moderno caracteriza-se pela busca incessante de ruptura com algo anterior: "Quando as palavras 'moderno', 'modernização' e 'modernidade' aparecem, definimos, por contraste, um passado arcaico e estável" (LATOUR, 1994, p.15). Nesse sentido, o projeto consiste em atividade eminentemente moderna, na medida em que apresenta um caráter analítico e crítico em relação ao que já existe. De acordo com Argan (1993), análise e crítica, por sua vez, realizam-se por meio da discriminação e da categorização ${ }^{1}$ do existente: primeiro deve-se levantar o que já foi feito, organizar em tipologias, observando-se o que há de comum e de diferente entre os diversos exemplares, para, depois, propor algo novo. 0 historiador da arte apresenta, então, um exemplo arquitetônico ${ }^{2}$ para mostrar como ocorre a discriminação e a categorização no projeto.

[...] se queremos saber o que é o tipo do templo circular, devemos pegar todos os templos circulares que conhecemos, fazer uma comparação entre eles e isolar as características que salientamos em todos os exemplos tomados. Evidentemente, não se deduz um templo circular de certa quantidade de templos circulares, mas podemos deduzir constantes, tais como proporções, constantes no número de colunas, constantes nas relações entre as colunas e as outras panes da arquitetura; é uma análise que estendemos a todos os objetos. Mas o que é esta análise? Esta análise destrói a característica específica de cada objeto para isolar uma função, uma tipologia que está sempre em

\footnotetext{
${ }^{1} \mathrm{O}$ processo de categorização, tão utilizado pelas ciências até hoje, constitui herança cartesiana na medida em que promove o conhecimento da realidade por meio da discriminação dos existentes e da tipificação por meio da identificação de suas características. Podemos perceber essa prática nos enciclopedistas do século XVIII, nas tipologias dos seres vivos promovidas pelas ciências biológicas no século XIX e nas mais variadas práticas científicas.

$2 \mathrm{O}$ texto de Argan fundamenta-se em exemplos arquitetônicos para apresentar a cultura do projeto. Podemos entender essa escolha por ter sido, na arquitetura, o primeiro momento em que ocorre a separação entre a elaboração intelectual e a execução, entre o planejamento (forethought) e o fazer (making). Como vimos anteriormente, Ingold (2013) mostra que, no século XV, o prefácio de Alberti constitui fonte que explicita claramente ser a arquitetura um campo intelectual não ligado à execução das edificações, cabendo a produção ao carpinteiro.
} 
relação com uma função. É sempre a ideia de uma função relacionada a um espaço, e que não tem uma determinação formal em si. É o momento que considero como fundamental no processo de projeto. É o momento no qual a experiência histórica é inteiramente levada a cabo, terminada. Percorremos, por assim dizer, todos os templos circulares para isolar esta imagem de templo circular. (ARGAN, 1993, p.2-3)

Podemos perceber que, no projeto, o processo de criação ocorre de maneira distinta daquele da cultura do modelo. Este consiste em uma forma que deve ser reproduzida como ela é, enquanto o tipo, identificado pelo projetista, constitui uma generalidade que não tem uma determinação formal definida, mas que pode servir de referência para a elaboração de uma proposta nova. O tipo, diferentemente do modelo, aponta para um futuro e esse futuro pressupõe o novo: "[...] numa concepção humanista e muito clara é absolutamente evidente que não se procura fazer um projeto que não seja um projeto de mudança de qualquer coisa que exista." (ARGAN, 1993, p.2). A partir da categorização do tipo, portanto, devem-se gerar hipóteses para, só então, analisar qual será a mais realizável para execução. E qualquer uma dessas hipóteses deve pressupor originalidade, já que a função do projeto "[...] é exercer sempre uma crítica sobre a existência, e supor qualquer coisa de diferente e evidentemente melhor" (ARGAN, 1993, p.4).

De modo semelhante, Rittel (apud HEINRICH, 2013, p.64) elenca as etapas do projeto: 1) definir o problema; 2) coletar informações; 3) analisar informações, relacionando-as; 4) desenvolver soluções; 5) avaliar alternativas; 6) testar e implementar a solução final para posterior produção. Essa listagem torna evidente que a concepção de projeto não inclui a etapa produtiva de execução, pois a cultura do projeto pressupõe a separação dicotômica entre ideação e produção. Esse processo de criação surge na arquitetura do Renascimento e expande-se para demais campos do conhecimento, como as engenharias e o design.

Essa ordem é corroborada por Lawson e Dorst (2009, p.30), que citam as seguintes etapas como componentes do projeto de design: 1) colocar a questão (pose); 2) pesquisar (search); 3) gerar alternativas (generate); 4) avaliar (evaluate); e 5) escolher (choose). Porém eles questionam ser a síntese necessariamente feita após a análise, ainda que pareça lógico ser a atividade sintética posterior ao recebimento do briefing e da análise do problema. Segundo esses autores (2009, p.58),

Pensar em soluções e pensar sobre problemas parecem ações inextricavelmente entrelaçadas no processo de design. [ ... ] Alguns campos do design têm problemas muito claramente definidos que podem ser muito bem descritos e compreendidos no início do processo ou muito precocemente. Outros podem ter problemas caracteristicamente mais abertos que só podem ser descritos de forma muito frouxa e apenas compreendidas vagamente no princípio. ${ }^{3}$

O processo do projeto, portanto, pode variar de acordo com a característica do trabalho. No caso de projetos com wicked problems, como os descritos por Buchanan (1995b), pode fazerse necessária outra sequência ou até mesmo idas e vindas, quando se vai do problema para a solução e se retorna da solução para o problema, como apresentado por Reyes (2012, p.92), sendo que esses retornos não se configuram como retrocessos, mas como parte do avanço, segundo Asimow (apud HEINRICH, 2013, p.68). Heinrich (2013, p.88) observa que tem havido uma

\footnotetext{
3 "Thinking about solutions and thinking about problems seem inextricably interwoven in the design process. [...] Some design fields have very clearly defined problems that can be quite well described and understood at the beginning of the process or very early in it. Others may characteristically have more open-ended problems that can only be very loosely described and only vaguely understood at the outset".
} 
tendência de mudança no campo do design e "[...] as estruturas projetuais têm evoluído de sistemas lineares e fechados para métodos cíclicos que permitem retornos flexíveis e adaptativos". Evidentemente, assim como o próprio campo se transforma e evolui, também se modifica a prática do projeto. Mas Bonsiepe (apud HEINRICH, 2013, p.71) já pontuava em 1978 que, independentemente de variações das metodologias, uma estrutura básica sempre está presente: definição do problema, análise e proposta. E concluía que as variações da metodologia do projeto beneficiavam, de fato, mais o acadêmico que o profissional, este último alheio a tantas variantes.

Projeto e metodologia são comumente tomados como sinônimos no campo do design, como mostrou Heinrich (2013) em sua pesquisa. Porém devemos ressaltar que existe uma dimensão criativa nesse processo, como apontou Reyes. Freitas (1999), em sua tese de doutorado, elaborou um questionário para aferir a percepção dos professores de design do Rio de Janeiro a respeito do campo. Nele, pediu que os professores escolhessem as cinco palavras-chave que servissem de base para a formulação de um conceito de design. O termo criatividade foi o mais mencionado, sendo que metodologia e projeto ficaram em segundo lugar empatados. Mas, curiosamente, quando perguntados sobre qual seria a essência da atividade, a criatividade ficou em terceiro lugar, atrás de metodologia de projetos e solução de problemas. Esse resultado decorre justamente do fato de o design ter como essência do projeto essas duas dimensões: a criatividade e a racionalidade. Escrevem, a esse respeito, Lawson e Dorst (2009, p.28): "[...] o design não é apenas uma forma de pensar, mas muitas. Particularmente é uma mistura de racionalidade, pensamento analítico e criatividade. Essa esquizofrenia inerente é a característica definidora do design [...]". ${ }^{4}$

Essa visão, ainda que compreenda o design como uma atividade que conjuga criação e razão, pressupõe uma oposição entre elas, uma vez que os autores entendem como esquizofrenia a possibilidade de aliar a capacidade criativa e a racional. Mesmo expressa com um toque de humor, tal afirmação revela, no fundo, um entendimento da realidade que acompanha o pensamento ocidental há séculos: razão e criação como polos diametralmente opostos. O objetivo desse artigo é mostrar como, ainda que a racionalidade seja, no campo, entendida como a fonte legitimadora do Design, a criatividade constitui parte fundamental da metodologia, o que torna o Design uma ciência da invenção e não da descoberta, como afirmado por Buchanan (1995a).

\section{A importância da metodologia no Design}

Segundo Heinrich (2013, p.60-61), a noção de metodologia de projeto em design começa a ser construída nas precursoras escolas de design na Alemanha, na primeira metade do século XX. A HfG Ulm (Hochschule für Gestaltung - 1952) é reconhecida como a pioneira no uso dessa noção, mas desde a criação da Deutscher Werkbund (Liga Alemã do Trabalho), em 1907, inicia-se o desenvolvimento desse conceito. A Deutscher Werkbund foi criada e era composta por profissionais de diferentes áreas, entre eles designers, arquitetos, comerciantes, empresários, com os objetivos de valorizar o design alemão, de buscar soluções para a má qualidade dos produtos industriais - porém sem promover o retorno da manufatura, como o movimento inglês Arts and

\footnotetext{
4 "[...] design is not one way of thinking, but several. In particular it is a mix of rational, analitycal thinking and creativity. This inherent schizophrenia is a defining characteristic of design [...]".
} 
Crafts fez $z^{5}$ - e de criar um padrão formal que desonerasse as indústrias às voltas com a estratégia de diferenciação dos produtos.

Desde a Revolução Industrial, como tratado anteriormente, as empresas, visando ampliar seus lucros, produziam várias versões para um mesmo artigo a fim de atender a necessidade de seus clientes de se diferenciar dos demais e de apresentar claramente seu papel perante a sociedade. Como escreve Forty (2013, p.95), o design "[...] oferecia sinais duradouros, visíveis e tangíveis das diferenças entre homens e mulheres tal como se acreditava que existissem", bem como entre crianças e adultos, entre empregados e patrões e entre as classes sociais que coexistiam na época. Porém essa estratégia, se por um lado ampliava os lucros, por outro aumentava os custos das empresas. Por isso, na Alemanha do início do século XX, buscou-se racionalizar o design dos produtos com vista a otimizar o processo produtivo, de forma a produzir artefatos de melhor qualidade. Por trás da Deutscher Werkbund havia, portanto, um objetivo estético, econômico e social, já que, diminuindo os custos e racionalizando a produção, seria possível produzir objetos mais baratos e acessíveis às classes menos abastadas. $O$ gérmen da noção de metodologia de projeto já estava, assim, plantado na Alemanha do início do século, uma vez que se buscava a racionalidade no processo produtivo e no processo de utilização, dando ênfase às funções práticas dos produtos.

Também na Alemanha, em 1919, surgiu a Bauhaus, sob forte influência da Deutscher Werkbund. Alguns de seus componentes faziam também parte da Liga Alemã do Trabalho: Henry Van de Velde (1863-1957), um dos mentores da Bauhaus; Walter Gropius (1883-1969), um dos fundadores da Bauhaus; Mies Van der Rohe (1886-1969), professor e último diretor da Bauhaus, entre outros. Iniciou-se, com essa escola, o processo de formalização e institucionalização do design. $O$ curso se organizava em três fases, em que havia um tom racional e artístico: idealizadora (etapa de conceituação), formativa (etapa de experimentação) e produtiva. Também tinha, como a Deutscher Werkbund, uma intenção social, buscando promover uma sociedade mais igualitária por meio do design. Dentro dos preceitos modernos, comprometia-se com a construção do novo (BOMFIM apud HEINRICH, 2013, p.62).

Porém foi com a Escola de UIm (HfG UIm), na década de 1950, que se buscou aprofundar a aproximação entre design e indústria, tendo como base o pensamento científico, uma vez que racionalidade, objetividade, neutralidade e universalidade ${ }^{6}$ eram valorizadas na primeira metade do século XX (CROSS, 1981, p.195). Para isso, as fases do projeto foram delimitadas e descritas segundo um critério racional, objetivando-se um processo menos subjetivo e procurando-se procedimentos seguros para se resolverem problemas cada vez mais complexos. Procurava-se, nesse período, desenvolver formas menos intuitivas de trabalho.

Podemos perceber, portanto, como a metodologia passou a ser uma forma de legitimação do design, ao se buscarem critérios "objetivos" para a resolução de problemas. Segundo Maldonado (apud HEINRICH, 2013, p.70), os métodos de projetação visam demonstrar que o sucesso de um trabalho não se deve a obra do acaso, mas é consequência de um pensamento

\footnotetext{
5 1907: Fundação do Deutscher Werkbund. Disponível em http://www.dw.com/pt/1907-fundação-do-deutscherwerkbund/a-3143195. Acesso em: 31 ago. 2015.

${ }^{6}$ Importante frisar que esses valores do método científico foram questionados na segunda metade do século XX, a partir do próprio desenvolvimento das ciências aplicadas, que verificaram haver fenômenos indeterminados e ser a pesquisa científica não objetiva e neutra, uma vez que o pesquisador acabava interferindo na realidade analisada. Um exemplo foi a descoberta do mundo do muito pequeno na física quântica.
} 
racional. Desse modo, muitos designers e teóricos até hoje consideram a metodologia o cerne do design. Como escreve Villas-Boas (apud HEINRICH, 2013, p.150), ela consiste na "[...] própria razão de ser do design". Portanto, vemos que a racionalidade e uma "possível" cientificidade7 é que vêm sendo eleitas as legitimadoras desse campo. Segundo Daniel Pink, em O cérebro do futuro (2007), há uma tendência, na sociedade ocidental, à supervalorização da nossa capacidade analítica, já que esta caracterizaria a inteligência humana. Isso pode revelar o porquê de a metodologia ser tão valorizada no meio.

\section{Segundo Bomfim (apud ABRAMOVITZ; MONTEIRO, 2002, p.4), método}

[...] deriva do vocábulo grego "métodos" e significa caminho para alguma coisa, seguir alguma coisa ou andar ao longo de um caminho. Neste sentido, método é a previsão de alguma tarefa que se desenvolve de um modo consciente e objetivo, ou seja, no senso comum um método é o planejamento que antecede uma tarefa.

Portanto, pela escolha e pelo uso de um método, o designer espera dar uma resposta a determinada questão de design, seguindo etapas que permitam a ele prever uma solução mais adequada a cada caso. A questão de design deve ser, desta maneira, mediada: a racionalidade do criador fará uma síntese das informações recebidas e pesquisadas a fim de antever um produto de design que atenda às necessidades e aos desejos específicos daquela situação. $O$ projeto pode ser entendido como um "[...] processo complexo de antecipação do futuro" (REYES, 2012, p.92). Podemos identificar as várias etapas comuns às metodologias, apontadas por Bonsiepe (apud HEINRICH, 2013, p.71), como processos relacionados à racionalidade: definição do problema, coleta de informações, análise de informações, avaliação de alternativas.

Na definição do problema - primeira etapa -, um cliente pode procurar um designer já com uma ideia clara do que deseja como projeto ou chegar com uma necessidade a fim de elaborar, juntamente com esse profissional, as questões principais que devem ser atendidas. No primeiro caso, temos uma visão de projeto próxima àquela que Herbert Simon explicitou no famoso livro As ciências do artificial, de 1981. Nessa publicação, o autor propõe o termo ciências do artificial para nomear um conjunto de ciências que têm como objeto artefatos - objetos não encontrados na natureza -, o que incluiria o design. O projeto, para esse autor, é uma forma de antecipação. O problema identificado por Paulo Reyes (2012, p.92), nessa concepção, é que Simon confia haver certeza na definição do problema, o que levaria a uma conclusão necessária. Por isso, Reyes explica que, desse ponto de vista, o projeto é entendido em sua anterioridade e critica:

\section{A ideia de "objetivo prévio" retira o pesquisador da própria ação projetual e o posiciona em uma perspectiva "anterior" ao projeto. Ou seja, o projeto é pensado de uma maneira a resolver todos os possíveis contratempos de um jeito pré-estabelecido [sic], já na construção do problema. Na busca por um "método de otimização", Simon constrói a precisão dos resultados com um controle total de todas as alternativas possíveis no processo. (REYES, 2012, p.92)}

No segundo caso, aproximamo-nos da ideia de Schön (2000), que entende o projeto em sua interioridade (Reyes, 2012, p.92): este ocorre no processo de construção de problemas, já que há uma dimensão de incerteza inerente a ele. Torna-se necessária, desta maneira, a "reflexão na ação" (SCHÖN, 2000): a construção do problema acontece no próprio momento em que se está agindo, pesquisando, atuando, em um processo de tentativa e erro. Percebe-se que essa visão é

\footnotetext{
${ }^{7}$ Veremos no próximo tópico que, segundo Cross (1981), o método científico difere do método em design por serem as ciências aplicadas e o design atividades totalmente distintas.
} 
similar ao conceito de wicked problems de Rittel e incorpora, para dentro da projetação, um elemento de acaso, fora do controle da recionalidade.

De qualquer forma, seja definido anteriormente pelo cliente, seja resultado de um processo do designer na reflexão na ação, a proposição do problema toma a forma de um briefing, que pode ser definitivo, conclusivo (como no primeiro caso citado) ou em construção, em aberto (como no caso dos wicked problems). Do inglês brief, resumo, consiste no primeiro documento a ser preparado e nele devem estar contidas todas as instruções para um bom desenvolvimento do trabalho: quais as necessidades e os desejos identificados em potenciais clientes; qual o perfil desses usuários; que características da empresa ou indivíduo que contrata o serviço devem ser evidenciadas e comunicadas; quais os possíveis concorrentes, entre outras.

Esse primeiro passo serve de norte para sistematizar a informação de cliente, designer(s) e demais envolvidos no processo, mas a solução do problema ainda não está evidente. A partir daí, seguem as etapas de coleta e análise de dados a fim de levantar informações adicionais que deverão servir de base para a criação. A pesquisa sobre a concorrência contribui para categorizar as respostas de outras empresas ou indivíduos em tipos, assim como foi visto em Argan (1993). Por exemplo: um fabricante de laticínios deseja lançar, no mercado, um novo iogurte que ofereça como diferencial ser sem lactose. O designer ou outros responsáveis no escritório ou agência podem fazer um levantamento de iogurtes com ou sem lactose a fim de observar e discriminar as características da embalagem, a saber: formato, material, dimensão, cores, formas, imagens, tipografias etc. Por meio do método indutivo, serão identificadas, portanto, as semelhanças e as diferenças entre elas, de forma a criar categorias gerais. Com base nessas tipologias, será feita, então, uma análise da adequação do tipo às características do produto e ao público-alvo: as embalagens para crianças devem apresentar-se de forma diferente, possivelmente, das de adultos; as sem lactose, das com lactose, e assim por diante. Diante dessa categorização racional, podem-se traçar possíveis caminhos para o novo projeto, considerando-se as informações sobre a aceitação dessas embalagens pelos consumidores, tendo em vista as vendas ocorridas.

Dentro da coleta e análise de dados, podemos destacar que a categorização do públicoalvo, tão importante de ser identificado para a definição clara do problema de design, também depende de um processo racional. Porém, Bernd Löbach (2001, p.55) afirma que o designer está, na verdade, pouco informado sobre usuários e suas necessidades. O reconhecimento da importância do conhecimento do público-alvo vem crescendo nas últimas décadas e, por isso, desde a década de 1980, as ciências sociais e o design têm se aproximado (SANDERS, 2002, p.1) a fim de contribuir com o aumento de informação sobre o repertório e o comportamento dos usuários. Jorge Frascara (2002, p.33) compreende a relação entre design e ciências sociais como um potencializador da eficiência do produto a ser criado. Considera que essa aproximação decorre do reconhecimento das mudanças no campo do design e da percepção de que essa transformação necessita de maior participação de cientistas sociais na concepção e no desenvolvimento de produtos e serviços.

Os métodos de pesquisa - utilizados pela etnografia, pelo marketing ou pela psicologia buscam o mesmo propósito: entender o repertório, o comportamento, o desejo e a necessidade do usuário, já que "Nenhum design funciona, exceto se encarna ideias que são comuns às pessoas para as quais o objeto se destina" (FORTY, 2013, p.330). Por isso, o aspecto racional da metodologia em design tem sido tão valorizado entre os profissionais do meio, já que é uma forma de antecipar um futuro que se deseja de sucesso para aquele que contrata o trabalho do 
designer. A última etapa desse processo - a análise das alternativas -, também subsumida à racionalidade, utiliza-se desse poder de previsão para avaliar qual a melhor alternativa, entre as criadas, deverá ter mais sucesso para resolver a questão de design.

Porém podemos perceber que a etapa de geração das hipóteses, parte fundamental das metodologias utilizadas no campo de design, possui característica diferente das que foram citadas até então. Quando um designer utiliza técnicas como mind maps (mapas mentais que ajudam a organizar relações e hierarquias entre conceitos), moodboards (quadros de referências que servem como objetos inspiracionais) (A.TELIER, 2011, p.22), brainstormings ("tempestades de ideias" que ajudam a estabelecer conexões inconscientes, ao buscarem eliminar o pensamento crítico), ele visa à síntese de ideias e conceitos. O cerne da criação - a geração de soluções para a questão de design - apresenta um caráter de liberdade e de potencialidade. E é justamente a presença desse frescor que torna o design uma ciência da invenção e não da descoberta, usando aqui a expressão proposta por Buchanan (1995a). A metodologia permite-nos sintetizar, generalizar e prever, mas solucionar problemas e oferecer respostas também depende da criatividade.

\section{Criatividade}

Como escreve Baxter (2000, p.51), "[...] a criatividade é o coração do design, em todos os estágios do projeto". E a valorização desse aspecto tem crescido nas últimas décadas. Pink (2007) escreve que, após séculos de predomínio das faculdades associadas ao lado esquerdo do cérebro - capacidade verbal, lógica e analítica -, tem surgido uma nova cultura que eleva o lado direito na sua capacidade sintética, não verbal e contextual -, como fundamental para o ser-humano. 0 autor lista três fatores que, segundo ele, levam a essa mudança: a automação, a globalização e a abundância. Em primeiro lugar, os trabalhadores superespecializados e processadores de informação, antes apreciados pelo mercado, foram substituídos por computadores. Em segundo, com a globalização esse tipo de trabalho analítico, agora menos lucrativo, foi sendo transferido para indivíduos de países emergentes, como Índia, enquanto o serviço mais valorizado - o sintético e criativo - passou a ser, nos países desenvolvidos, tarefa dos profissionais mais bem preparados (aqui cabe destacar que Pink, embora não explicite isso em seu livro, está ressaltando a transformação da sociedade e do mercado para essa nova cultura apenas nos países desenvolvidos, pois os emergentes acabam ficando com as atividades menos valorizadas dos trabalhos). Em terceiro lugar, o autor cita a abundância: em um mercado tão saturado, a capacidade criativa torna-se fundamental para diferenciar um produto de outro, fazendo-o destacar-se. Como escrevem Ingold e Hallam (2007, p.1),

Em um mercado de commodity global com apetite insaciável por coisas novas, em que cada aspecto da vida e da arte é convertido em um objeto de fascinação ou de desejo de ser apropriado e consumido, a criatividade passou a ser vista como um importante motor da prosperidade econômica e bem-estar social. ${ }^{8}$

Esses autores afirmam ainda que, se analisarmos os títulos de livros que tratam de criatividade, perceberemos que a maior parte se encontra nas seções de gestão e de negócios. Por

\footnotetext{
8 "In a global commodity market with an insatiable appetite for new things, where every aspect of life and art is convertible into an object of fascination or desire to be appropriated and consumed, creativity has come to be seen as a major driver of economic prosperity and social well-being".
} 
isso, essa capacidade humana tem sido considerada chave para o sucesso comercial e empresarial.

Segundo a artista plástica Fayga Ostrower (1987, p.9), criar é dar forma a algo. E nessa conformação do objeto de design não atua somente a racionalidade, mas também a criatividade, pois o criador tem, como ponto de partida, potencialidades para a materialização de um novo existente. $O$ designer, por exemplo, com base nas definições, objetivos e estratégias descritos no briefing e pautado nas pesquisas sobre concorrência e público-alvo, escolherá as características as qualidades - que julgar mais adequadas para gerar o produto. Antes de ele estar pronto, ainda na fase de ideação, o produto consiste apenas em potencialidade de forma, de textura, de cor, de dimensão etc. As hipóteses geradas no projeto apresentam a variedade de possibilidades de configuração que o produto pode ganhar. Mas apenas uma será escolhida para ser determinada na realidade.

É por essa capacidade sintética do design de solucionar problemas e apresentar soluções novas que Pink (2007) elege essa atividade como o cerne da nova cultura, que ele nomeia de "era conceitual", em oposição a "era da informação", antes valorizada. O design, para ele, apresenta uma forma de pensar diferente daquela das atividades puramente analíticas, e, por isso, o designer consegue trabalhar de forma menos especializada e mais integrativa, dialogando com diversas áreas a fim de sintetizar uma solução para problemas cada vez mais complexos.

Cross (1982, p.221), conforme abordamos brevemente na introdução, aponta o "pensar" do design como uma terceira forma de apreender e pensar o mundo de forma a lidar com ele. De acordo com esse autor, àquela época a pesquisa sobre design e educação do Royal College of Arts, do Reino Unido, apontou para a existência de três culturas, e não apenas duas, sob as quais a habilidade e o conhecimento humanos se fundam. Além das ciências e das humanidades - que têm papel fundamental na educação escolar britânica - há, segundo o estudo, o design, que tem sido negligenciado no ensino fundamental. Propõe-se, então, que esse campo não seja incorporado à formação dos alunos como uma atividade especializada, mas como uma forma de ajudar os alunos a desenvolverem habilidades cognitivas, prepará-los para os papéis sociais e ajudá-los a lidar com a vida, já que o design possui uma forma característica de pensamento: uma forma de conhecimento designerly.

Cross conclui, a partir do relatório do Royal College of Arts, que "a principal questão no design consiste na concepção e na realização de novas coisas"9 (CROSS, 1982, p.221). Esse campo lida com a cultura material e com a aplicação das artes do planejar, inventar e fazer. A pesquisa realizada por esse instituto elenca aquilo que diferencia o design das ciências e das humanidades: 1) com relação aos métodos: as ciências trabalham com experimentos controlados, classificação e análise; as humanidades, com analogia, metáfora, criticismo e avaliação; já o design utiliza-se da modelagem e da síntese. 2) com relação aos valores: as ciências prezam objetividade, racionalidade, neutralidade, tendo interesse pela "verdade"; as humanidades valorizam subjetividade, imaginação, compromisso, buscando a "justiça"; já o design ocupa-se da praticidade, da criatividade, da empatia, visando à "adequação". 3) com relação aos fenômenos estudados: as ciências lidam com o mundo natural; as humanidades, com a experiência humana; já o design se volta para os artefatos humanos (man-made world) - ideia similar à de Simon (1981). Embora a Royal College of Arts apresente as diferenças entre as três culturas para mostrar

\footnotetext{
9 "The central concern of Design is 'the conception and realization of new things'".
} 
a especificidade do design em relação às ciências e às humanidades, podemos perceber que Cross enfatiza, em seus exemplos, a diferenciação entre ciência e design. Talvez isso se deva ao fato de ter o design, ao longo de sua história, buscado se aproximar do método científico como forma de legitimação, sendo as diferenças entre design e humanidades mais óbvias. Vamos, então, nos deter em cada uma dessas diferenças para compreender a forma designerly de conhecimento e de criação.

Lawson (LAWSON; DORST, 2009, p.28; CROSS, 1982, p.223) realizou um experimento em 1979 para investigar se haveria diferença entre a estratégia de resolução de problemas de designers e não designers. Ele apresentou, para estudantes de pós-graduação em ciências e em arquitetura (designers ${ }^{10}$ ), blocos coloridos tridimensionais para que fossem arranjados de acordo com algumas regras. Pôde-se observar que os cientistas começaram analisando a estrutura do problema, a fim de compreendê-la como uma primeira etapa para solucionar a questão. Por outro lado, os designers começaram, em forma de tentativa e erro, projetando soluções com a finalidade de avaliar qual delas respondia melhor ao problema: se a solução encontrada não se adequasse a esse problema, criavam uma alternativa para ver se esta nova atendia ao que era proposto. Eles concluíam o problema sem necessariamente entender sua estrutura de forma completa. Pôde-se perceber que a compreensão da questão, por parte dos designers, decorria de encontrarem a resposta adequada, em um caminho inverso. Isto é, os cientistas analisavam, compreendiam e sugeriam uma resposta, enquanto os designers sugeriam respostas, verificavam a adequação, e, então, compreendiam o problema. Por isso concluiu-se que a estratégia dos cientistas focava, de forma analítica, no problema, enquanto a dos designers focava, de forma sintética, na solução. Evidentemente há vantagens e desvantagens em cada orientação. Cientistas, ao analisarem a estrutura e procurarem descobrir a regra subjacente, conseguiam atingir uma resposta mais eficiente; por outro lado, ficavam mais limitados pelo problema. Os designers, de forma diversa, lidavam com mais criatividade em suas respostas, porém sem a certeza de serem efetivos. No caso de wicked problems, mal estruturados, a estratégia do designer mostrava-se a melhor.

Essa relação entre a estratégia de resolução de problemas e a efetividade da sua resposta decorre das características dos tipos de inferências utilizadas por estas culturas: ciências e design. $\mathrm{Na}$ resolução orientada para o problema, podemos identificar principalmente os argumentos dedutivo e indutivo, enquanto na orientada para a solução, podemos reconhecer especialmente o abdutivo, cerne das ideias inovadoras, como veremos a seguir. Na estratégia dos cientistas para o problema proposto por Lawson, dadas determinadas regras e a configuração dos blocos, eles buscaram, por indução, entender a regra subjacente à questão, de forma a, posteriormente, deduzir as possibilidades de combinação e testar a resposta. Os estudantes buscavam conhecer, portanto, a terceiridade que determinava as combinações e, por isso, as respostas oferecidas eram muito mais eficientes que as dos designers. Como afirma Liszka (1996, p.60),

A dedução pode ser entendida como uma inferência que nos permite expandir ou tornar o sistema mais complexo apenas com base na informação que já está contida nele. Ela não descobre novas informações, mas torna explícito o que já está implícito no sistema, mas

\footnotetext{
${ }^{10}$ A arquitetura pode ser entendida como campo distinto do design, como ocorre em algumas instituições, mas também, de forma diferente, como uma área dentro de um espectro maior: o design. De qualquer forma, independente da posição em relação a essa questão, ambas são atividades de projeto.
} 
que não se encontra diretamente expresso. ${ }^{11}$

Porém as soluções dos designers, justamente por não partirem de um pensamento analítico, mas de uma inferência abdutiva, mostraram-se mais ampliativas que as dos cientistas, mas menos seguras.

A sugestão abdutiva vem a nós como um flash, é um ato de insight, embora de insight extremamente falível. É verdade que os diferentes elementos da hipótese estavam em nossas mentes antes; mas é a ideia de juntar o que nunca se tinha sonhado em juntar anteriormente que clareia a nova proposta ante nossa contemplação. ${ }^{12}(C P, 5.181)$

A abdução, portanto, gera novas ideias, que são, em sua essência, falíveis. Desta maneira, esse tipo de inferência não determina a verdade nem gera certezas, mas apenas a plausibilidade de uma hipótese. Enquanto a dedução é rica em segurança, a abdução o é em liberdade e abertura.

Para mostrar como ocorre o processo de criação de soluções em design, Lawson e Dorst $(2009$, p.36) apresentam mais um exemplo da estratégia de pensamento do projetista. Eles citam o estudo de Jane Darke, que identificou um procedimento comum a arquitetos. Eles criavam uma solução em um estágio ainda muito precoce de entendimento do problema recebido, a que ela nomeou gerador primário (primary generator), que consistia em uma ideia ainda vaga de como a solução poderia ser, mas que permitia ao arquiteto criar várias hipóteses e, a partir delas, conhecer melhor o problema.

Essas conjecturas abdutivas próprias dos designers podem ser facilitadas por um processo que o filósofo Charles Sanders Peirce (2003, p.100) nomeia de puro jogo.

Há certa ocupação mental aprazível que, por não possuir nome distintivo, infiro que não seja tão comumente praticada quanto merece; pois, tolerada moderadamente, - digamos, durante algo como cinco ou seis por cento do tempo desperto de alguém, talvez durante um passeio - é suficientemente recreativa, mais do que para recompensar o dispêndio. Porque não envolve propósito algum, salvo aquele de pôr de lado todo propósito sério [...]

No puro jogo, a mente fica à mercê do devaneio, contemplando o mundo e fazendo analogias livres de objetivos futuros. No devanear, existe a possibilidade de surgimento de inferências abdutivas que podem vir a ser promissoras. Para Peirce, nós temos a capacidade de criar hipóteses explicativas do universo, que, muitas vezes, se mostram frutíferas, pois "Nossa faculdade de adivinhar corresponde aos poderes musicais e aeronáuticos de um pássaro; ou seja, ela é para nós, como aqueles são para eles, o mais sublime dos nossos poderes meramente instintivos $^{13 \prime \prime}(C P, 7.48)$. Por isso, ele $(C P, 6.461)$ afirma:

Não há nenhum tipo de raciocínio que gostaria de desencorajar no Devaneio; e eu lamentaria encontrar qualquer pessoa limitando-o a um método de criatividade tão moderada quanto a análise lógica. [...] eu diria "Entre em seu barco de devaneio, lance-o no lago do pensamento e deixe a brisa do paraíso encher suas velas. Com seus olhos

\footnotetext{
11 "Deduction can be thought of as an inference which allows us to expand or complicate the system just on the basis of the information that is already contained in the system. It doesn't discover new information so much as make explicit what information is already implicit in the system but not directly expressed".

12 "The abductive suggestion comes to us like a flash. It is an act of insight, although of extremely fallible insight. It is true that the different elements of the hypothesis were in our minds before; but it is the idea of putting together what we had never before dreamed of putting together which flashes the new suggestion before our contemplation".

13 "Our faculty of guessing corresponds to a bird's musical and aeronautical powers; that is, it is to us, as those are to them, the loftiest of our merely instinctive powers".
} 
abertos, acorde para o que está a sua volta ou dentro de você e comece uma conversação aberta consigo mesmo; porque tudo isso é meditação". No entanto não é uma conversa em palavras somente, mas ilustrada, como uma palestra, com diagramas e experimentos. ${ }^{14}$

Os diagramas são apontados, na citação peirciana acima, como parte do processo de criação livre e, por isso, fundamentais para operações heurísticas, estruturando os argumentos abdutivos (IBRI, 2009, p.288). Eles consistem em um modelo por semelhança que representa um esquema de relações identificado em fenômenos observados de forma estrutural. Por exemplo, "um geômetra desenha um diagrama, que se não é exatamente uma ficção, é ao menos uma criação, e, por meio da observação desse diagrama, ele pode sintetizar e mostrar relações entre elementos que antes não pareciam ter conexão necessariamente" ${ }^{15}(C P, 1.383)$. Fazendo uma associação, podemos perceber que um designer pensa na forma de um esboço, estabelecendo relações entre as informações coletadas, e, por isso, o pensamento diagramático também foi identificado por Alexander (apud CROSS, 1982, p.224) como fundamental no modo de pensamento do designer. Os mapas mentais, as analogias e os brainstormings são, por exemplo, tipos de diagramas que ajudam o designer a perceber conexões e estabelecer relações entre elementos aparentemente diferentes. Mas o pensamento diagramático só se torna funcional sob a égide da racionalidade, ao se compreenderem as regras que o regem (BUNDGAARD; STJERNFELT, 2010, p.70).

O raciocínio diagramático consiste em construir um diagrama conforme um preceito expresso em termos gerais, sobre o qual são realizados experimentos, sendo que toda dedução envolve a observação de um diagrama, criado a partir da observação de um estado de coisas e cujo fim será representá-lo. Qualquer que seja o tipo de dedução, cujas premissas estejam delineadas, é certo nele encontrar uma conclusão, a partir das relações representadas. (JORGE, 2002, p.9)

Por isso, ao fim do devaneio e do pensamento abdutivo, após a elaboração de hipóteses, as inferências dedutivas e indutivas tornam-se necessárias a fim de se verificar a adequação do produto concebido como solução ao problema proposto, já que no design não existem soluções corretas, mas adequadas, sendo que a própria escolha do processo projetual impacta no resultado (DE MORAES, 2010, p.XV).

Chegamos, após essa longa análise do modo de pensamento designerly, à segunda e à terceira diferenciação que a Royal College of Arts fez do design em relação às duas outras culturas (científica e humanidades): os valores e os fenômenos estudados. Relembrando, a pesquisa identificou ser o design um campo que se ocupa da praticidade, da criatividade, da empatia, visando justamente à adequação, tendo como seu objeto os artefatos humanos. Já as ciências se ocupam da "verdade", prezando pela objetividade, racionalidade e neutralidade, focando no mundo natural. Como abordamos anteriormente, embora possamos questionar se ainda hoje a

\footnotetext{
14 "There is no kind of reasoning that I should wish to discourage in Musement; and I should lament to find anybody confining it to a method of such moderate fertility as logical analysis. [...] I should say, 'Enter your skiff of Musement, push off into the lake of thought, and leave the breath of heaven to swell your sail. With your eyes open, awake to what is about or within you, and open conversation with yourself; for such is all meditation.' It is, however, not a conversation in words alone, but is illustrated, like a lecture, with diagrams and with experiments".

15 "The geometer draws a diagram, which if not exactly a fiction, is at least a creation, and by means of observation of that diagram he is able to synthesize and show relations between elements which before seemed to have no necessary connection".
} 
ciência é considerada determinista e neutra, é interessante observar como os valores e objetos de cada cultura se relacionam com as inferências praticadas. As ciências a que se refere Cross (1982), que lidam principalmente com pensamento dedutivo e indutivo, estão preocupadas em desvendar a regra por detrás dos fenômenos, isto é, revelar o que já existe, mas que não se encontra diretamente expresso. Por outro lado, o design pauta-se primordialmente na criação de hipóteses como forma de conhecer o problema e, portanto, consiste em um campo mais falível pela sua natureza, uma atividade "da invenção" e não "da descoberta", conforme afirmou Buchanan (1995a). De acordo com Simon (1982), as ciências naturais ocupam-se de como as coisas são, enquanto o design, de como as coisas podem ser.

O processo de criação no design alterna análise e síntese a fim de criar soluções para questões levantadas. Como escreve Kneller (1968, p.16), "a novidade criadora emerge em grande parte do remanejo de conhecimento existente - remanejo que é, no fundo, acréscimo ao conhecimento". Portanto, a geração de hipóteses surge no devaneio a partir de relações encontradas no conhecimento adquirido anteriormente e, nesse sentido, é fundamental a ampliação do repertório do designer para que ele tenha mais elementos em mente que possam ser relacionados e sintetizados em uma solução projetual. Nas etapas do processo de criação baseadas em pesquisa, objetiva-se, justamente, o ganho de conhecimento por parte daqueles que estão criando para que, nas etapas metodológicas sintéticas, se possa utilizar o pensamento diagramático a fim de estabelecer novas relações.

\begin{abstract}
Dentro de suas interações, os designers se movimentam, conversam, olham e tocam dispositivos, projetam e constroem artefatos, desenham esboços e desenhos mais precisos, escrevem ou fazem anotações em documentos de papel, usam ferramentas instaladas em uma estação de trabalho para acessar, armazenar, modificar e/ou criar documentos virtuais e assim por diante. Ao fazer qualquer uma dessas ações, eles conversam, falam consigo mesmos, associam palavras com o que eles tocam e olham (A.TELIER, 2011, p.63) $)^{16}$
\end{abstract}

Podemos perceber que a criação depende intimamente do ganho de repertório por parte do designer e do intercâmbio de repertórios do designer e demais atores participantes do projeto - clientes, fornecedores, entre outros - para que surjam alternativas para a questão de design que está em jogo. Porém a síntese é apenas uma parte do processo de criação. Se, no início, as relações, que levam à geração de alternativas, aparecem de forma difusa, como potencialidades, a partir da análise racional pode-se avaliar quais dessas relações fazem sentido como criação. Diferentemente de Maldonado (apud HEINRICH, 2013, p.70), que entende o método como um regulador da fantasia, concordamos com Fuentes (apud HEINRICH, p.58), para quem a metodologia de projeto objetiva ampliar o conhecimento sobre um problema, com a finalidade de melhor sustentar a criação, já que "O ato criador abrange [...] a capacidade de compreender; e esta, por sua vez, a de relacionar, ordenar, configurar, significar" (OSTROWER, 1987, p.9).

O designer, portanto, utiliza-se, no processo de criação, dos três tipos de inferências: a indução permite, a partir da discriminação e da categorização dos concorrentes, generalizar as características do que já foi feito; a dedução contribui para, a partir do conhecimento da generalidade do público-alvo, entender como deve ser o público, para que o produto seja bem

\footnotetext{
16 "Within their interactions, designers move about, converse, look at and touch devices, design and build artifacts, draw sketches and more precise drawings, write or annotate paper documents, use tools installed on a workstation to acess, store, modify, and/or create virtual documents, and so on. While doing any of these actions, they converse, they talk to themselves, they associate words with what they touch and look at".
} 
sucedido; e a abdução possibilita criar hipóteses possíveis e passíveis de serem materializadas, que servirão como base para futuras induções e deduções, já que da hipótese será deduzida uma consequência do uso desse produto e poderá ser feito um protótipo para ser testado - por indução - para verificar se a hipótese é a mais adequada para o problema de design (e, se não for, nova abdução poderá gerar novas alternativas, e assim por diante). Como escreve Peirce em "Um argumento negligenciado para a realidade de Deus" ("A neglected argument for the reality of God"), o puro jogo, que constitui o cerne da criação, não tem regras e não possui propósito, porém, depois dessa etapa, a lógica deverá entrar em ação. As três inferências, desta maneira, complementam-se, já que a dedução aprofunda o conhecimento, sendo explicativa, enquanto a indução e a abdução são ampliativas (LISZKA, 1996, p.30).

\section{Conclusão}

Constatamos que a polarização que comumente se faz na área de design entre criatividade e metodologia, bem como entre criatividade e raciocínio lógico - polarização esta que nos levou a abordar separadamente cada um desses aspectos -, de fato não existe. A metodologia possui um aspecto criador e o ímpeto de criação necessita do pensamento sintético para relacionar elementos antes não relacionados, gerando soluções inusitadas. Conforme escreveu Ostrower (1987, p.71), "A atividade criativa consiste em transpor certas possibilidades latentes para o real". Por isso o design consiste em uma ciência da invenção, que seleciona certas qualidades potenciais - as julgadas mais adequadas para atender à questão desejada - a fim de serem materializadas como produtos: novos existentes na realidade. Concluindo, mostra-se importante romper com uma visão tradicional polarizada, para compreender que síntese e análise não são processos opostos, mas complementares. Criatividade e raciocínio lógico, portanto, conjugam capacidades dedutivas, indutivas e abdutivas, responsáveis pela criação do novo no design.

\section{Referências}

1907: Fundação do Deutscher Werkbund. Disponível em: http://www.dw.com/pt/1907-fundaçãodo-deutscher-werkbund/a-3143195. Acesso em: 31 ago. 2015.

ABRAMOVITZ, José; MONTEIRO, Valéria Alvim. Reflexões sobre o ensino de design. In: P\&D 2002, 2002. AEND-BR Associação de Ensino de Design do Brasil.

ARGAN, Giulio Carlo. A história na metodologia do projeto. Revista Caramelo, São Paulo, n. 6, p.156-170. 1993.

A.TELIER, et al. Design things. Massachusetts: The MIT Press, 2011.

BUCHANAN, Richard. Rhetoric, humanism and design. In: BUCHANAN, Richard; MARGOLIN, Victor (Eds.). Discovering design. Explorations in design studies. Chicago e Londres: The University of Chicago Press, 1995a. p.23-66.

Wicked problems in design thinking. In: BUCHANAN, Richard; MARGOLIN, Victor (Eds.). The idea of design. Cambridge e Londres: The MIT Press. 1995b. p.3-20.

BAXTER, Mike. Projeto de produto: guia prático para o design de novos produtos. São Paulo: Edgard Blücher, 2000. 
BUNDGAARD, Peer; STJERNFELT, Frederik. Logic and cognition. In: COBLEY, Paul (Ed.). The Routledge companion to semiotics. Abingdon e Nova lorque: Routledge, 2010. p.57-73.

CROSS, Nigel. Design method and scientific method. Design Studies, Cambridge, v.2, n.4, p.195201, out. 1981.

FORTY, Adrian. Objetos de desejo: design e sociedade desde 1750. São Paulo: Cosac Naify, 2013.

FRASCARA, Jorge. People-centered design: complexities and uncertainties. In: FRASCARA, Jorge (Ed.). Design and the Social Sciences: Making Connections. Taylor \& Francis, 2002, p.33-39.

HEINRICH, Fabiana Oliveira. Crítica à noção de metodologia de projeto. 2013. 242 f. Dissertação (Mestrado em Design) - Pontifícia Universidade Católica do Rio de Janeiro (PUC-Rio), Rio de Janeiro, 2013.

HALLAM, Elizabeth; INGOLD, Tim. Creativity and cultural improvisation: an introduction. In: Creativity and cultural improvisation. Oxford e New York: Berg, 2007.

INGOLD, Tim. Making. Nova lorque: Routledge, 2013.

KNELLER, George F. Arte e ciência da criatividade. São Paulo: Ibrasa, 1968.

LATOUR, Bruno. Jamais fomos modernos: ensaio de antropologia simétrica. Rio de Janeiro: Ed. 34, 1994.

LAWSON, Bryan; DORST, Kees. Design expertise. Oxford: Elsevier, 2009.

LISZKA, James Jakób. A general introduction to the semeiotic of Charles Sanders Peirce. Bloomington e Indianapolis: Indiana University Press, 1996.

LÖBACH, Bernd. Design industrial: bases para a configuração dos produtos industriais. São Paulo: Blucher, 2001.

OSTROWER, Fayga. Criatividade e o processo de criação. Petrópolis (RJ): Vozes, 1987.

PEIRCE, Charles Sanders. Um argumento negligenciado para a realidade de Deus. Cognitio, São Paulo, v. 4, n. 1, p.98-133, jan./jun. 2003.

. The collected papers of Charles Sanders Peirce. Electronic edition. Virginia: Past Masters, 1994. Disponível em: <http://library.nlx.com/>.

PINK, Daniel H. O cérebro do futuro: a revolução do lado direito do cérebro. Rio de Janeiro: Elsevier, 2007.

REYES, Paulo. Projetando pela exterioridade do projeto. Strategic Design Research Journal, v.5, n.2, p.91-97, mai./ago. 2012.

SANDERS, Elizabeth B. N. From user-centered to participatory design approches. In: FRASCARA, Jorge (Ed.). Design and the social sciences: Making Connections. Taylor \& Francis, 2002. p.1-8.

SCHÖN, Donald Alan. Educando o profissional reflexivo: um novo design para o ensino e a aprendizagem. Porto Alegre: Artmed, 2000.

SILVA, Sérgio Luciano da; SILVA, Sérgio Antônio. 0 conceito aristotélico de Mímesis aplicado ao processo criativo em design. Estudos em Design, Rio de Janeiro, v. 21, n. 1, p .1-22. 2013. 